\section{Unusually persistent complainants}

\author{
GRANT LESTER, BETH WILSON, LYNN GRIFFIN and PAUL E. MULLEN
}

\begin{abstract}
Background Querulous paranoia may have disappeared from the psychiatric literature, but is it flourishing in modern complaints organisations and the courts?
\end{abstract}

\begin{abstract}
Aims To investigate the unusually persistent complainants who lay waste to their own lives and place inordinate demands and stress on complaints organisations.
\end{abstract}

\begin{abstract}
Method Complaints officers completed questionnaires on both unusually persistent complainants and matched controls.
\end{abstract}

Results Persistent complainants (distinguished by their pursuit of vindication and retribution) consumed time and resources and resorted to both direct and veiled threats. Attempts to distinguish these people from a control group on the basis of the manner in which their claims were initially managed failed.

Conclusions Persistent complainants' pursuit of vindication and retribution fits badly with complaints systems established to deliver reparation and compensation.

These complainants damaged the financial and social fabric of their own lives and frightened those dealing with their claims. The study suggests methods of early detection and alternative management strategies.

Declaration of interest None.
The querulant and the paranoid litigant once occupied a privileged position among psychiatric disorders (Krafft-Ebing, 1879; Kraepelin, 1904; Kolle, 1931; Kretschmer, 1934; Heydt, 1952). Such people were regarded as inhabiting the borderline between delusional psychosis and the fanatical preoccupations of the psychopathic personalities (Jaspers, 1923; Schneider, 1958; McKenna, 1984). Clérambault (1942) included them in his 'psychoses passionelles', and they found their way into both the ICD and DSM classificatory systems (Pichot, 1982). Although occasional studies of vexatious litigants continue to appear (Rowlands, 1988; Freckelton, 1988; Caduff, 1995), the category fell into disrepute, undermined by criticisms that it was doing no more than pathologising those with the energy and commitment to pursue their rights (Stalstrom, 1980). Querulousness retreated into obscurity just as complaint was coming to occupy a central position in maintaining the social compact in Western culture (Douglas, 1992). The querulous, given the current neglect of this category, now pass largely unrecognised and unregarded by mental health professionals (Ungvari et al, 1997).

Complaints organisations and the courts continue to be plagued by a small group of unusually persistent people who consume enormous amounts of resources. This study addressed the nature of this group, whether its members resembled those described in the old literature on querulousness, and if there was evidence that the way in which their claims had been dealt with initially had launched them on this disastrous course.

\section{METHOD}

\section{Study group}

Experienced complaints professionals were recruited from six ombudsmen's offices in
Australia. These agencies of accountability receive secondary referrals following a failure to resolve initial complaints. They deal with many thousands of complaints every year, covering a range of governmental, business and professional activities. These complaints professionals completed a questionnaire on those they had identified as unusually persistent complainants from among their cases that were no longer active. A senior person in each organisation checked that there was no duplication and that no identifying information had been inadvertently included. For each case identified, the professionals selected as a control the next case on their register in which the person was the same gender and general age, whose complaint was broadly similar, and whose case was also closed. An identical questionnaire was completed for the control and again supplied without any identifying material.

\section{The questionnaire}

The questionnaire was compiled through consultation with focus groups of complaints officers and a review of the existing literature on the querulous (a copy of the questionnaire is available from the authors upon request). The human research ethics committee of the Department of Human Services, Victoria, approved the study.

\section{Statistical analysis}

Fisher's exact test (two-sided) with $P<0.05$ as a cut-off was employed with the odds ratio to measure the size of the effect, and simple one-way analysis of variance (ANOVA) for the association or explained variance.

\section{RESULTS}

Ninety-six valid questionnaires were returned out of 110 distributed (52 persistent cases and 44 controls). Nearly threequarters $(72 \%)$ of the 'persistent' group were men. The control group was matched for gender, but the population of clients dealt with by the organisations had a 48:52 male-female ratio, suggesting a marked overrepresentation of men in the persistent group.

\section{Factors defining persistence}

The mean period of involvement with the complaint organisations for the persistent group was longer (35 months $v .8 .3$ 
months, $P<0.01$ ), and a significantly smaller proportion of the persistent cases were resolved at closure $(23 \% v .87 \%$, $P<0.01$ ), compared with the control group. There was no significant difference between the two groups in whether the person registered the complaint by letter (persistent group $81 \% v$. control group $82 \%)$ or telephone $(90 \% v .77 \%)$, or made an appointment to see someone personally $(23 \% v .23 \%)$. The persistent complainants were more likely to turn up without an appointment $(31 \% v .4 .5 \%$, odds ratio 9.3, 95\% CI $2.0-43.4 ; P<0.01)$ and to communicate by e-mail $(19 \% v .4 \%$, OR $5.0,95 \%$ CI $1.03-24.2 ; P<0.05)$ and fax (56\% v. 32\%, OR 2.7, 95\% CI 1.2-6.2; $P<0.05)$. In the persistent group, $71 \%$ used three or more methods to communicate, compared with only $34 \%$ of controls (OR 3.43, 95\% CI 1.47-8.0; $P<0.01$ ). Persistent complainants communicated more frequently and at far greater length (Table 1) and demanded changes in case worker more often $(52 \% v$. 9\%, OR 19.4 , 95\% CI 4.5-88.8; $P<0.01$ ).

\section{Nature and aim of the complaints}

The persistent and control groups were equally likely to complain of specific losses and damage to finances $(71 \% v .72 \%$; NS), relationships $(25 \%$ v. $18 \% ; \mathrm{NS})$ and physical functioning (15\% v. 5\%; NS). The persistent more frequently complained of damage to their overall social and economic functioning $(35 \% \quad v .9 .5 \%$, OR 5.3, 95\% CI 1.6-17.2; $P<0.01$, self-esteem $(40 \% v$. $14 \%$, OR $4.3,95 \%$ CI $1.5-11.9 ; P<0.01)$ and general health (44\% v. 23\%, OR 2.6, 95\% CI 1-6.6; $P<0.05)$. The professionals, in contrast, judged the persistent group less likely to have incurred actual financial loss $(39 \%$ v. $59 \%$, OR $0.5,95 \%$ CI $0.2-1.01$; $P<0.05)$ and no more or less likely to have sustained damage to their health or relationships. Overall, the professionals judged some $31 \%$ of the persistent group to have sustained no substantial loss compared with only $9 \%$ of the control group (OR 2.8, 95\% CI 99-7.98; $P<0.05$ ).

Compensation, usually financial, was frequently sought by those in both persistent and control groups $(61 \%$ v. $58 \%$; $\mathrm{NS})$, as were improved services (42\% $v$. $47 \%$; NS). Acknowledgement that they had been mistreated and some form of specific apology were more often sought by the persistent $(67 \% v$. $32 \%$, OR 4.4 , 95\% CI 1.9-10.4; $P<0.01$ ).

The differences between the two groups' objectives became clearer when issues of personal vindication and retribution were considered. The persistent sought acknowledgement of the wider social implications of their complaint (39\% v. 9\%, OR 6.3, 95\% CI 1.9-20.1; $P<0.01)$ and public recognition of their struggles $(25 \%$ v. $0 \% ; P<0.01)$. Retribution, in terms usually of the dismissal or prosecution of those they held responsible, was sought more frequently by the persistent $(43 \% v .11 \%$, OR $5.7,95 \%$ CI $1.9-16.9 ; P<0.01)$. More extreme forms of revenge, such as public exposure and humiliation, were demanded exclusively by the persistent $(14 \% v .0 \% ; P<0.01)$. The persistent more often demanded justice for themselves based on claims of principle (60\% v. 18\%, OR 9.98, 95\% CI 3.7-26.8; $P<0.01)$ and insisted on their 'day in court' (25\% v. 4\%, OR 7.0, 95\% CI 1.4-33.0; $P<0.01)$. The professionals found that the persistent were more likely to vary the nature and grounds of their complaint over time $(31 \%$ v. $0 \% ; P<0.01)$.

\section{Form of the complaints}

The form in which the complaints were expressed showed more idiosyncrasies in the persistent group. Persistent complainants were more likely to use medical and legal terms inappropriately: legal, $42 \% v$. $2 \%$, OR $31.5,95 \%$ CI $4.03-246$ $(P<0.01)$; medical, $19 \%$ v. $2 \%$, OR $10.24,95 \%$ CI $1.3-83.5(P<0.01)$. The use of rhetorical questions, such as 'Should any reasonable person be made to accept such treatment?' in written communications was more common among the persistent: $56 \% v .7 \%$, OR $17.2,95 \% \mathrm{CI}$ 4.7-62.8 $(P<0.01)$.

The written material from the persistent complainants showed unusual methods of attempting to emphasise their words (Table 1). The use of highlighters to accentuate certain words occurred in both the persistent and control groups, but the use of several different colours to highlight words was significantly more common in the persistent group: $19.2 \%$ v. $2.3 \%$, OR 10.2 , 95\% CI $1.3-83.5 \quad(P<0.01)$. The

Table I Forms of emphasis or methods of drawing attention to the merits of the claim and the complainant used by persistent complainants (cases) and people in the control group

\begin{tabular}{|c|c|c|c|c|c|}
\hline Factor & $\begin{array}{c}\text { Controls } \\
\text { (\%) }\end{array}$ & $\begin{array}{c}\text { Cases } \\
(\%)\end{array}$ & Odds ratio $(95 \% \mathrm{Cl})$ & $P$ & $\begin{array}{c}\text { Correlation coefficients } \\
\qquad \eta^{21}\end{array}$ \\
\hline More than 10 letters & 9 & 60 & I $4.8(4.6-47.7)$ & 0.01 & 0.35 \\
\hline Letters of more than 100 pages & 2.7 & 25 & $17.4(2.2-138)$ & 0.01 & 0.20 \\
\hline More than 10 telephone calls & 7 & 64 & $23.7(6.5-87.1)$ & 0.01 & 0.32 \\
\hline Telephone calls over $60 \mathrm{~min}$ & 9 & 60 & I3.6 (4.3-43.7) & 0.01 & 0.24 \\
\hline Sends copies of other letters & 9 & 35 & $4.8(2.0-11.5)$ & 0.01 & 0.15 \\
\hline Sends personal endorsements or references & 2 & 25 & |4.3 (I.8-||14.7) & 0.01 & 0.18 \\
\hline Multiple capitals & 9 & 50 & $10.0(3.1-32.0)$ & 0.01 & 0.15 \\
\hline Repeated underlining & 10 & 56 & $12.6(3.9-40.4)$ & 0.01 & 0.16 \\
\hline Repeated inverted commas & 11.4 & 40 & $4.5(1.5-13.3)$ & 0.05 & 0.15 \\
\hline Multiple comments in margins & 11.4 & 32.7 & $3.8(1.3-11.3)$ & 0.01 & 0.20 \\
\hline Three or more forms of emphasis & II & 57 & $10.6(3.6-31.4)$ & 0.01 & 0.31 \\
\hline
\end{tabular}

I. The correlations provided are with the variable duration of this episode of complaining. 
more traditional methods of emphasis were also employed significantly more frequently, including repeated underlining, using inverted commas and inserting marginal notes. Three or more of these typographical forms of emphasis were found in over half of the persistent $157 \%$ v. $11 \%$ ). The professionals judged that the methods used by the persistent of expressing their written complaints, compared with the control group, were inappropriately lengthy and difficult to follow $(95.5 \% v .17 \%$, OR $0.01,95 \%$ CI $0.002-0.049 ; P<0.01$ ); the various oddities of writing also on occasion rendered parts of the letters from the persistent group unintelligible $(42 \% v .2 \% ; P<0.01)$. The persistent complainants showed a greater propensity to attach supporting materials to their written complaints, including copies of letters, almost invariably with added comments and copies of supporting documents $(35 \%$ v. $9 \% ; P<0.01)$. The enclosing of endorsements of their good character and personal diaries was confined to the persistent $(15.4 \% v .0 \%)$.

\section{Behaviour of complainants}

Complaints officers judged the persistent complainants to be more difficult and intimidating. Interestingly, only people from the persistent group were judged to have behaved in an overly ingratiating manner (42\% v. $0 \% ; P<0.01)$. Written threats against the complaints professionals were made exclusively by the persistent, $17 \%$ of whom made direct threats and 32\% veiled threats, such as 'I know where you live' and 'Careful you don't find yourself losing your family like me'. Threats over the telephone or in person were also made exclusively by the persistent $(52 \%)$. Similarly, only the persistent made threats to kill themselves $(16 \%)$ if their complaint were not settled to their satisfaction. Overtly offensive $(22 \%$ v. $0 \% ; P<0.01)$ and overly dramatic expressions $(77 \% v$. 7\%, OR 45.5, 95\% CI 11.9-173.6; $P<0.01$ ) were employed more frequently by the persistent, as were unnecessary repetitions $(71 \% v .11 \%$, OR $19.2,95 \%$ CI $6.3-58.2 ; P<0.01)$. In interviews only about $10 \%$ of the persistent group were found by professionals to be able to express their complaints in a coherent and rational manner $(10.5 \% v .82 \%$, OR $0.03,95 \%$ CI $0.003-0.21 ; P<0.01)$. Complaints officers experienced a positive rapport, or at least active sympathy, less frequently with the persistent complainants $(12 \% v .86 \%$, OR 0.02 , 95\% CI $0.01-0.07 ; P<0.01)$. Professionals acknowledged attempting more frequently to avoid contact with these complainants $(48 \%$ v. $0 \% ; P<0.01)$ and seeking help from senior colleagues $(52 \%$ v. 2\%, OR 54.2, 95\% CI 6.9-424.0; $P<0.001)$. The persistent complainants themselves were more likely to involve other agencies as the complaints procedure progressed, with $77 \%$ contacting at least one other agency $(v .21 \% ; P<0.001)$, and $37 \%$ contacting four or more $(v .0 \%$; $P<0.01)$.

\section{Management of the initial complaint}

The complaints professionals attempted to evaluate how the complaint had been handled initially. In their view, only about half of all the complaints from both the case and the control groups had been dealt with appropriately and reasonably by the agency, or individual, receiving the initial complaint ( $53 \% v .46 \%$; NS). Unreasonable delay had occurred on occasion for both persistent and control complainants (25\% v. 30\%; NS), and people in both groups had on occasion been met with overt hostility ( $8 \%$ v. $2 \%$; NS), a blanket denial $(23 \% v .18 \%$; NS) or suggestions they had only themselves to blame $(8 \% v$. $2 \%$; NS). Subsequently there was not judged to be any significant difference in how often unreasonable expectations were fostered about the likely nature of the settlement ( $4 \%$ v. $2 \%$; NS).

\section{Impact on the complainants}

Persistent complainants were reported as having a far greater investment in their claim, being far less likely to view a failure as 'disappointing' ( $19 \% v .91 \%$, OR 0.024 , 95\% CI $0.007-0.082 ; P<0.01)$ and more likely to describe the consequences as a 'disaster' $(81 \%$ v. $9 \%$, OR $42,95 \%$ CI $12.1-144 ; P<0.01)$ or even 'life-threatening' (23\% v. $0 \% ; P<0.01)$, compared with the control group. By pursuit of their claim, those in the persistent category were more likely than controls to have damaged their close relationships ( $31 \%$ v. $2 \%$, OR 19.1 , 95\% CI 2.4-15.1; $P<0.01)$ and their social lives $(25 \%$ v. $0 \% ; P<0.01)$, and to have seriously impaired their financial position (29\% v. $7 \%$, OR $5.5,95 \%$ CI $1.5-20.6$; $\mathrm{P}<0.01)$.

\section{Analysis of variance}

The ANOVA demonstrated that $31 \%$ of the variance in the persistence of the claimants was predicted by variables related to the methods of expressing the grievance, including the style and language of the complaints, which was present from the outset, and the volume of materials, which accumulated as the complaints procedure progressed.

\section{DISCUSSION}

The unusually persistent pursued their complaints for longer, supplied more written material, telephoned more often and for longer, intruded more frequently without an appointment, and ultimately were still complaining when the case was closed or transferred. They differed from the control group as predicted in being motivated at least in part by desires for vindication and retribution, in the curious and dramatic forms in which they presented their claims, in how they behaved while pursuing their claims - particularly with regard to threats - and in how high a price personally and socially they paid for that pursuit.

\section{Vindication and retribution}

The persistent complainants focused on issues of personal vindication and retribution. This fits badly with the functions of complaints organisations, and even court-based litigation, which are geared to provide conciliation through reparation and compensation. These people are searching for outcomes that a modern complaints resolution process cannot deliver. A more formal orientation for complainants at the outset, reinforced if necessary over time, about what can (and what cannot) be provided in the complaints process might militate against the pursuit of such unrealisable goals.

\section{Form of the complaints}

The increased frequency and the voluminous nature of the material generated by the persistent group were to be expected. Less predictable were the dramatic differences in the form in which complaints were registered. Unusual methods of emphasis included multiple underlinings, putting words in capital letters, and the liberal use of exclamation marks and inverted commas, as well as copious marginal notes. 
Interestingly, exactly these types of emphasis are reported in descriptions of querulants in the 19th and early 20th centuries (Krafft-Ebing, 1879; Kraepelin, 1904). Emphasising words with multiple-coloured highlighting pens is a modern variant, which we have also seen clinically among our querulant patients, some of whom produce a riot of colour on every page of their voluminous complaints. Other features described in the earlier literature were the frequent misuse of technical legal and medical terms, and the attachment to the complaints of copies of letters, reports of legal decisions, personal endorsements and diaries. These visible and easily quantifiable similarities between the forms in which today's persistent complainants and yesterday's querulants express their grievances is a strong argument for an overlap between the two groups. These peculiarities in the form in which the complaints are presented accounted for over a third of the variance between cases and controls in our study. As these idiosyncrasies are usually present from the outset, they potentially provide an early warning sign.

\section{Threats and damages}

Over half of the persistent complainants made some form of threat of violence directed at the complaints professionals. Equally troubling was the frequency of suicide threats. These threats explain the apprehensiveness about personal safety expressed by many of the professionals when dealing with the unusually persistent. We had assumed the group we saw clinically differed from the vast majority of unusually persistent complainants in having resorted to threats and violence. The study indicates, however, that threats are very much a part of the behaviour of the querulant. Whether or not the person is prosecuted and referred to a forensic clinic is at least in part a function of the tolerance of the complaints officers. The fears expressed in the focus groups about the social and interpersonal damage suffered by the persistent complainants were also confirmed by the study. These findings underline the importance of complaints organisations both making strenuous efforts to protect and support their staff who deal with such cases, and doing all in their power either to prevent or to extricate persistent complainants from their damaging progress.

\section{CLINICAL IMPLICATIONS}

- Unusually persistent complainants not only seriously disrupt their social and financial functioning but also by threatening and intrusive behaviour frighten and distress those attempting to help them.

- These complainants, in addition to seeking compensation and reparation, are in pursuit of personal vindication and retribution, aims incompatible with modern complaints procedures.

- The manner in which the persistent claimants pursue their quest for justice and the form in which they express their complaints are clearly separable from the methods used by the vast majority of complainants and show a remarkable similarity to those described in the classic literature as characteristic of the querulous and vexatious.

\section{LIMITATIONS}

- The study method did not allow examination of the claimants' experiences and state of mind, which can only be surmised from the observations of the complaints officers.

- The study was limited to 52 cases and 44 controls.

- The study method could not distinguish between the people studied being at the extreme end of a continuum of complainants and their being a qualitatively different group.

GRANT LESTER, FRANZCP, BETH WILSON, LLB, LYNN GRIFFIN, MEd, PAUL E. MULLEN, DSc, Victorian Institute of Forensic Mental Health, Office of the Health Services Commissioner, Department of Psychological Medicine, Monash University, Victoria, Australia

Correspondence: Professor Paul E. Mullen, Thomas Embling Hospital, Locked Bag 10, Fairfield, Victoria 3078, Australia. E-mail: paul.mullen@dhs.vic.gov.au

(First received 2 June 2003, final revision 27 October 2003, accepted 12 November 2003)

\section{Creating the persistent complainant}

One of our hopes in conducting this study was to establish that inept and socially insensitive responses early in the progress of the complaint contributed to the chronicity and recalcitrance of the persistent group. If such provocations could be identified, they might be remediable. The failure to obtain direct evidence that persistent complainants were more likely to be subjected to hostile, rejecting or blaming responses may reflect our dependence on the second-hand, and potentially partial, impressions of the professionals. Had we been able to obtain direct access to the complainants' experiences of their initial contacts, a different picture might have emerged. This area merits further research.

\section{Assessing the risk of unusual persistence}

The behaviours that differentiated the persistent cases from the controls were nearly always apparent by the time the complaint reached an agency of accountability, although the severity often escalated over time, as the frustrations and distress mounted. Even on the basis of this preliminary study, it should be possible to identify at an early stage many of those at risk of becoming abnormally persistent. This capacity is worse than useless, however, unless it leads to a response that could decrease the damage suffered by the complainant - worse than useless, because in the absence of effective interventions then identification would amount to stigmatisation. The next phase of research 
needs, therefore, to include properly controlled trials of methods of complaint management aimed at preventing the emergence of these destructive forms of persistence. Better induction of clients into the complaints process is one possibility. Another is actively identifying and attempting to counter unrealistic and essentially unrealisable goals. A trial might be worthwhile using teams of professionals trained specifically for managing the abnormally persistent complainant. The conventional wisdom is that difficult clients should be managed by a single experienced professional, to avoid splitting and confusion. This conventional wisdom is probably correct for the difficult complainant, but not necessarily for the unusually persistent: here, a team of professionals who can share the load and protect each other from becoming the specific focus of the client's ire might be more effective. These possibilities need proper evaluation.

Mental health professionals have, over recent decades, stepped back from involvement with those once viewed as querulous - or have been pushed back. There are good reasons for caution in introducing concepts of personal pathology into social processes such as complaining, but equally it is cavalier to ignore the possibility that knowledge and approaches developed in the mental health field might offer help to organisations and individuals in avoiding the damaging and distressing effects of unusually persistent complaining. Perhaps it is time to restore querulousness to a legitimate place among the problem behaviours that mental health professionals study and manage.

\section{REFERENCES}

Caduff, F. (1995) Querulanz - ein verschwindendes psychopathologisches Verhaltensmuster? Forschritte der Neurologie Psychiatrie, 63, 504-510.

Clérambault, G. de (192I) Les psychoses passionelles. Reprinted 1942 in Oeuvres Psychiatriques, pp. 315-322. Paris: Presses Universitaires de France.

Douglas, M. (1992) Risk and Blame: Essays in Cultural Theory. London: Routledge.

Freckelton, I. (1988) Querulent paranoia and the vexatious complainant. International Journal of Law and Psychiatry, II, 127-143.

Heydt, A. van der (1952) Querulatoische Entwicklungen Halle: Marhold.
Jaspers, K. (1923) General Psychopathology. Reprinted 1963 (trans. J. Hoenig \& M.W. Hamilton). Manchester: Manchester University Press.

Kolle, K. (1931) Über Querulanten. Archiv für Psychiatrie und Nervenkrankheiten, 95, 24-102.

Kraepelin, E. (1904) Lectures in Clinical Psychiatry (trans. \& ed. T. Johnson). London: Baillière, Tindall \& Cox.

Krafft-Ebing, R. von (1879) Über den sogenannten Querulantenwahnsinn. Allgemeine Zeitschrift der Psychiatrie, 35, 395-419.

Kretschmer, E. (1934) A Textbook of Medical Psychology (4th edn) (trans. E. B. Strauss). Oxford: Oxford University Press.

McKenna, P. J. (1984) Disorders with overvalued ideas. British Journal of Psychiatry, 145, 579-585.

Pichot, P. (1982) The diagnosis and classification of mental disorders in French-speaking countries: background, current views and comparison with other nomenclatures. Psychological Medicine, 12, 475-492.

Rowlands, M.W. (1988) Psychiatric and legal aspects of persistent litigation. British Journal of Psychiatry, 153, 317-323.

Schneider, K. (1958) Psychopathic Personalities (9th edn, trans. M. W. Hamilton). London: Cassell.

Stalstrom, O.W. (1980) Querulous paranoia: diagnosis and dissent. Australian and New Zealand Journal of Psychiatry, 14, 145-150.

Ungvari, G., Pang, A. \& Wong, C. (1997) Querulous behaviour. Medicine, Science and the Law, 37, 265-270. 